\title{
ChemComm
}

Check for updates

Cite this: Chem. Commun., 2017, 53,5432

DOI: $10.1039 / \mathrm{c7cc90160g}$

rsc.li/chemcomm

\section{Correction: Light up detection of heparin based on aggregation-induced emission and synergistic counter ion displacement}

\author{
Shiwu Li, ${ }^{a}$ Meng Gao, ${ }^{a}$ Shuxia Wang, ${ }^{b}$ Rongrong Hu, ${ }^{a}$ Zujin Zhao, ${ }^{a}$ Anjun Qin*a and \\ Ben Zhong Tang*ac
}

Correction for 'Light up detection of heparin based on aggregation-induced emission and synergistic counter ion displacement' by Shiwu Li et al., Chem. Commun., 2017, 53, 4795-4798

The heparin structures shown in the graphical abstract, Fig. 1 and 6 were incorrect. The corrected versions of Fig. 1 and 6 are shown below and the graphical abstract has been updated.

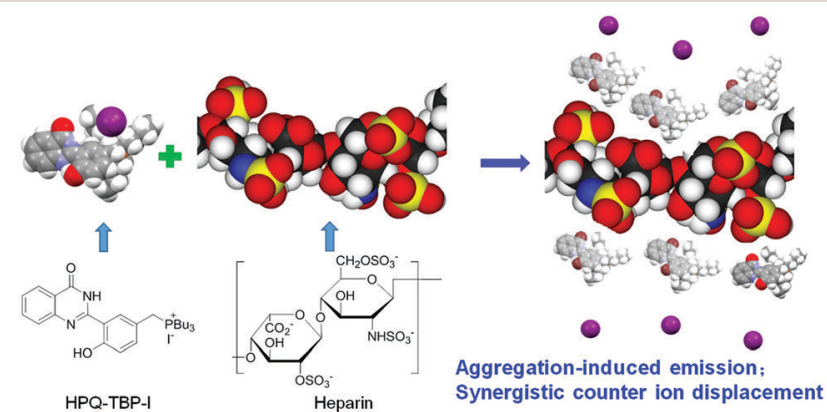

Fig. 1 Illustration of the detection principle of HPQ-TBP-I for heparin.
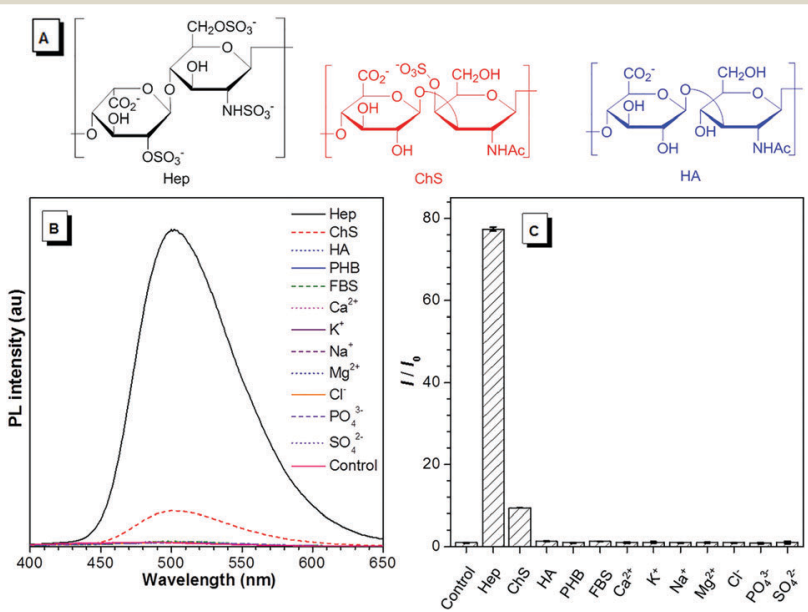

Fig. 6 (A) Chemical structure of Hep, ChS and HA; (B) PL spectra of HPQ-TBP-I in aqueous solution treated with different biomolecules and ions (10 $\mu$ M), respectively; and $(C)$ ratio of the relative $P L$ intensity $\left(I / I_{0}\right)$ at $501 \mathrm{~nm}$ with various biomolecules and ions. $[\mathrm{PHB}]=[\mathrm{FBS}]=0.05 \mathrm{mg} \mathrm{mL}^{-1} ;[\mathrm{HPQ}-\mathrm{TBP}-\mathrm{I}]=100 \mu \mathrm{M} ; \lambda_{\mathrm{ex}}=330 \mathrm{~nm}$.

The Royal Society of Chemistry apologises for these errors and any consequent inconvenience to authors and readers.

\footnotetext{
${ }^{a}$ State Key Laboratory of Luminescent Materials and Devices, South China University of Technology, Guangzhou 510640, China. E-mail: msqinaj@scut.edu.cn

${ }^{b}$ Department of Nuclear Medicine, Guangdong General Hospital, Guangdong Academy of Medical Sciences, Guangzhou 510080, China

${ }^{c}$ Department of Chemistry and Hong Kong Branch of Chinese National Engineering Research Center for Tissue Restoration and Reconstruction,

The Hong Kong University of Science \& Technology, Clear Water Bay, Kowloon, Hong Kong, China. E-mail: tangbenz@ust.hk
} 